\title{
Subtle changes in strain prior to sub-Plinian eruptions recorded by vault-housed extensometers during the 2011 activity at Shinmoe-dake, Kirishima volcano, Japan
}

\author{
Ken'ichi Yamazaki ${ }^{1}$, Masahiro Teraishi $^{1}$, Kazuhiro Ishihara ${ }^{2 *}$, Shintaro Komatsu ${ }^{3}$, and Koji Kato ${ }^{4}$ \\ ${ }^{1}$ Miyazaki Observatory, Research Center for Earthquake Prediction, DPRI, Kyoto University, 3884 Kaeda, Miyazaki 889-2161, Japan \\ ${ }^{2}$ Sakurajima Volcano Research Center, DPRI, Kyoto University, Sakurajima-Yokoyama, Kagoshima 891-1419, Japan \\ ${ }^{3}$ Miyazaki Observatory, Division of Technical Affairs, DPRI, Kyoto University, 3884 Kaeda, Miyazaki 889-2161, Japan \\ ${ }^{4}$ Fukuoka District Meteorological Observatory, Japan Meteorological Agency, 1-2-36, Ohori, Chuo, Fukuoka 810-0052, Japan
}

(Received March 11, 2013; Revised September 6, 2013; Accepted September 7, 2013; Online published December 6, 2013)

\begin{abstract}
This study focuses on strain change observations with a precision of $10^{-9}$ associated with the 2011 Shinmoedake eruptions in Japan, using vault-housed extensometers installed approximately $18 \mathrm{~km}$ northwest of the Shinmoe-dake crater. The extensometers recorded major strain changes of $10^{-7}$ during three sub-Plinian eruptions and subsequent magma effusion. Our analysis indicates that these extensometer records provide a reasonable estimation of the parameters of an isotropic point source that can explain eruption-related ground deformation. The extensometers also recorded subtle strain changes of $10^{-9}$ prior to the three sub-Plinian eruptions. Time series data indicate that changes in strain at these rates are generally only observed immediately before explosive eruptions, suggesting that these strain changes are precursors to sub-Plinian eruptions. The source of these subtle strain changes is likely to be shallower than the magma chamber associated with these eruptions. The precursory strain changes might have been caused by a pressure increase and a subsequent pressure decrease under the volcano. One possible scenario that can explain these pressure changes is the accumulation of volcanic gases at depth, causing an increase in pressure that was eventually released during gas emissions from the crater prior to the explosive eruptions.
\end{abstract}

Key words: Extensometer, explosive eruption, sub-Plinian eruption, Shinmoe-dake volcano, Kirishima volcanic group, crustal deformation, magma chamber.

\section{Introduction}

Some important views on the dynamics of volcanic eruptions owe their origins to precise observations of eruptionrelated crustal deformations of the order of $10^{-9}$ in strain and tilt. Previous research has demonstrated that subtle ground deformation occurs prior to the eruptions of some volcanoes, as has been observed using vault-housed extensometers at Sakurajima in Japan (e.g., Kamo and Ishihara, 1986; Ishihara, 1990; Iguchi et al., 2008) and Piton de la Fournaise in the Réunion Islands (Peltier et al., 2007), and by high-precision tiltmeters and dilatometers at the Soufrière Hills volcano on Montserrat (Voight et al., 1998, 1999, 2010; Druitt et al., 2002; Chardot et al., 2010; Linde et al., 2010). Measuring and studying such deformations are clearly important if we are to understand the eruption processes of volcanoes.

However, previously reported examples of eruptionrelated crustal deformation have not documented all possible types of eruptive activity, and continuous crustal defor-

\section{* Retired.}

Copyright (C) The Society of Geomagnetism and Earth, Planetary and Space Sciences (SGEPSS); The Seismological Society of Japan; The Volcanological Society of Japan; The Geodetic Society of Japan; The Japanese Society for Planetary Sciences; TERRAPUB.

doi:10.5047/eps.2013.09.005 mation observations, especially high-precision strain observations, have only been undertaken on a few active volcanoes (e.g., Dvorak and Dzurisin, 1997; Peltier et al., 2007). The majority of routine observations have been conducted on volcanoes that frequently erupt (e.g., Linde et al., 1993; Peltier et al., 2007; Iguchi et al., 2008). As a consequence, less frequent events, such as Plinian or sub-Plinian eruptions, have rarely been investigated using continuous crustal deformation data with a precision of $10^{-9}$. This situation contrasts sharply with Vulcanian eruptions that have been intensively investigated (e.g., Chardot et al., 2010; Linde et al., 2010; Voight et al., 2010).

Shinmoe-dake, one of the volcanic cones in the Kirishima volcanic group (Fig. 1), erupted in January 2011. This was the first major eruption of Shinmoe-dake in 52 years, although minor eruptions frequently occur, such as those in 1991 and 2010. The 2011 activity was characterized by three sub-Plinian eruptions that were followed by the effusion of magma from the summit crater over 6 days between 26 and 31 January, 2011. This activity was monitored using a dense geophysical network including a global positioning system (GPS) and observations of tilting conducted by several institutions (e.g., Nakao et al., 2013; Ueda et al., 2013). In addition, the Shinmoe-dake activity was observed by vault-housed extensometers at a site approximately $18 \mathrm{~km}$ from the summit of the crater (Fig. 1) 


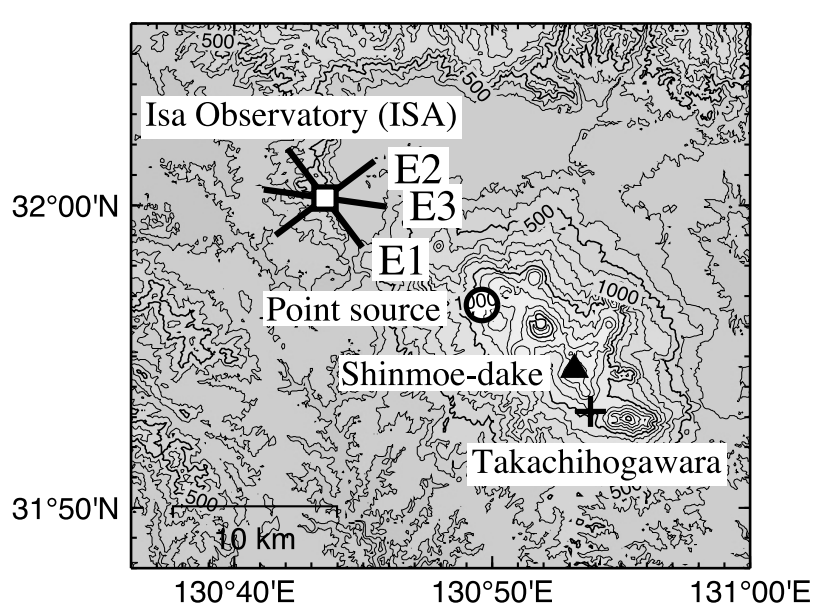

Fig. 1. Map showing the location of the Shinmoe-dake volcano crater (solid triangle) and the ISA site (open square) where strain data were recorded. Thick bars at the ISA site show the directions of extensometers, and contours indicate the surface topography at $100 \mathrm{~m}$ intervals. An open circle represents the location of a magma chamber proposed by the Geospatial Information Authority using GPS data, with a cross representing the location of the Takachihogawara seismic station of the Japan Meteorological Agency, where seismograms are recorded in a 100-m-deep borehole.

\section{(Yamazaki et al., 2011).}

This paper presents extensional ground strain data with a precision of $10^{-9}$, or better, obtained during the most recent eruptions of Shinmoe-dake. In particular, we demonstrate precursory ground deformations of a type that has not previously been recognized.

\section{Vault-housed Strain Observations near the Shinmoe-dake Cone and Their Resolution}

Strain observations using vault-housed extensometers were obtained at the Isa-Yoshimatu observatory (ISA, at $\left.32^{\circ} 00^{\prime} 14.4^{\prime \prime} \mathrm{N}, 130^{\circ} 43^{\prime} 31.4^{\prime \prime} \mathrm{E}\right)$. The summit crater of Shinmoe-dake (N31 ${ }^{\circ} 54^{\prime} 34^{\prime \prime}$, E130 $53^{\prime} 11^{\prime \prime}$; Japan Meteorological Agency, 2005) is $18.5 \mathrm{~km}$ from the ISA site at an azimuth of $\mathrm{S} 55.48^{\circ} \mathrm{E}$ (Fig. 1). The ISA consists of tunnels in three directions, E1 $\left(\mathrm{N} 37^{\circ} \mathrm{W}\right), \mathrm{E} 2\left(\mathrm{~N} 53^{\circ} \mathrm{E}\right)$, and E3 $\left(\mathrm{N} 82^{\circ} \mathrm{W}\right)$. Each tunnel houses extensometers made up of 30-m lengths of super-invar rods (Fig. 2). One end of each extensometer is fixed to the ground, and the other end is free. Displacement of the free end is measured at 1-s intervals using a differential transformer, and the amount of displacement is divided by the length of the rod to obtain the ground extension (strain) in the corresponding direction.

The precision of the strain measurement data at ISA is $1 \times 10^{-9}$ in the E1 and E3 directions. The precision of the E2 component, obtained during the 2011 eruption of Shinmoedake, is somewhat poorer than the precision of the E1 and E3 components, at around $2-3 \times 10^{-9}$, primarily because the electrical system in this part of the vault was damaged during a lightning strike one month before the eruption.

The large distance between the Shinmoe-dake crater and ISA observatory means that the strain data obtained at ISA may be less sensitive to volumetric changes of subsurface pressurized magma than at facilities elsewhere that are closer to the volcanoes being observed. Vault-housed ex-

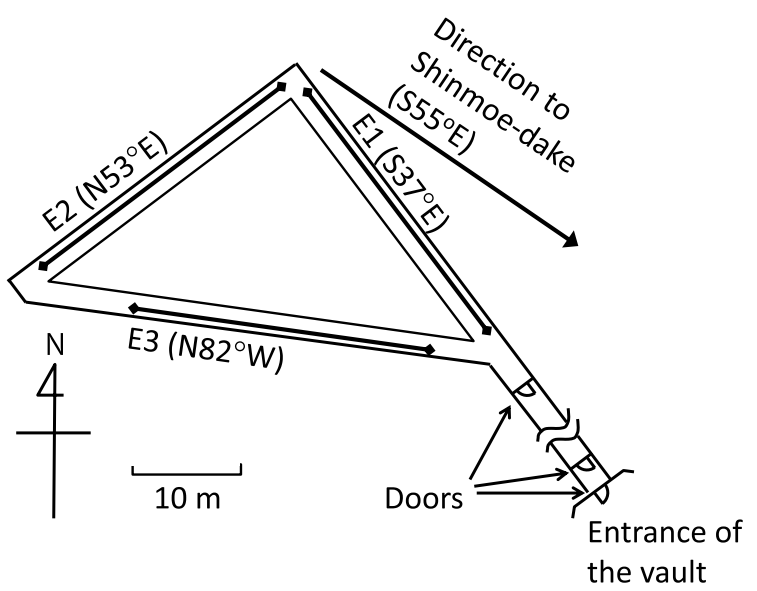

Fig. 2. Plan view of the observational setup at ISA.

tensometers for monitoring specific volcanoes are usually installed at distances less than several kilometers, as exemplified by the vault-housed extensometers at the Harutayama observatory near the Minamidake crater of Sakurajima volcano. These extensometers have similar geometries (i.e., three components arranged in a triangular shape) and lengths $(\sim 30 \mathrm{~m})$ to the extensometers at ISA, but the distance between the crater and the observatory is $<3 \mathrm{~km}$ (e.g., Kamo and Ishihara, 1986).

Nevertheless, we can confirm that the somewhat distal extensometers at ISA are more sensitive to some types of subsurface volume changes than are GPS-based measurements. Assuming that the resolution of displacement using GPS is up to $1 \mathrm{~mm}$, the detection limit for subsurface volume changes using extensometers located $20 \mathrm{~km}$ away from the source epicenter is much better than when using densely deployed GPS, except in the case of an extremely shallow source $(\sim 1 \mathrm{~km}$; see Appendix for detail).

\section{Strain Changes Associated with Major Erup- tive Events}

The most prominent phenomena involved in the 2011 activity of Shinmoe-dake were three sub-Plinian eruptions on 26 and 27 January, 2011, and the subsequent effusion of magma during 28-31 January, 2011. All these events were accompanied by major variations in strain that were recorded at the ISA site. The temporal strain variations are shown in Fig. 3. Strain variations were characterized by an extension in the E1 component and by contraction in the E2 component. The E1 component approximately coincides with the direction of the Shinmoe-dake volcano from the ISA observatory (Fig. 1), indicating that this component is nearly radial to the eruptive vent. In comparison, the E2 direction is perpendicular to this direction and as such is nearly transverse to the eruptive vent.

To clarify the nature of the strain changes generated during the eruptions, we estimated eight major strain timeseries tidal components and removed them from the original time series. This was done using the algorithm proposed by Tamura et al. (1991) based on Akaike Bayesian Information Criteria (ABIC; Akaike, 1980). Although the underground recording of strain data by extensometers is 


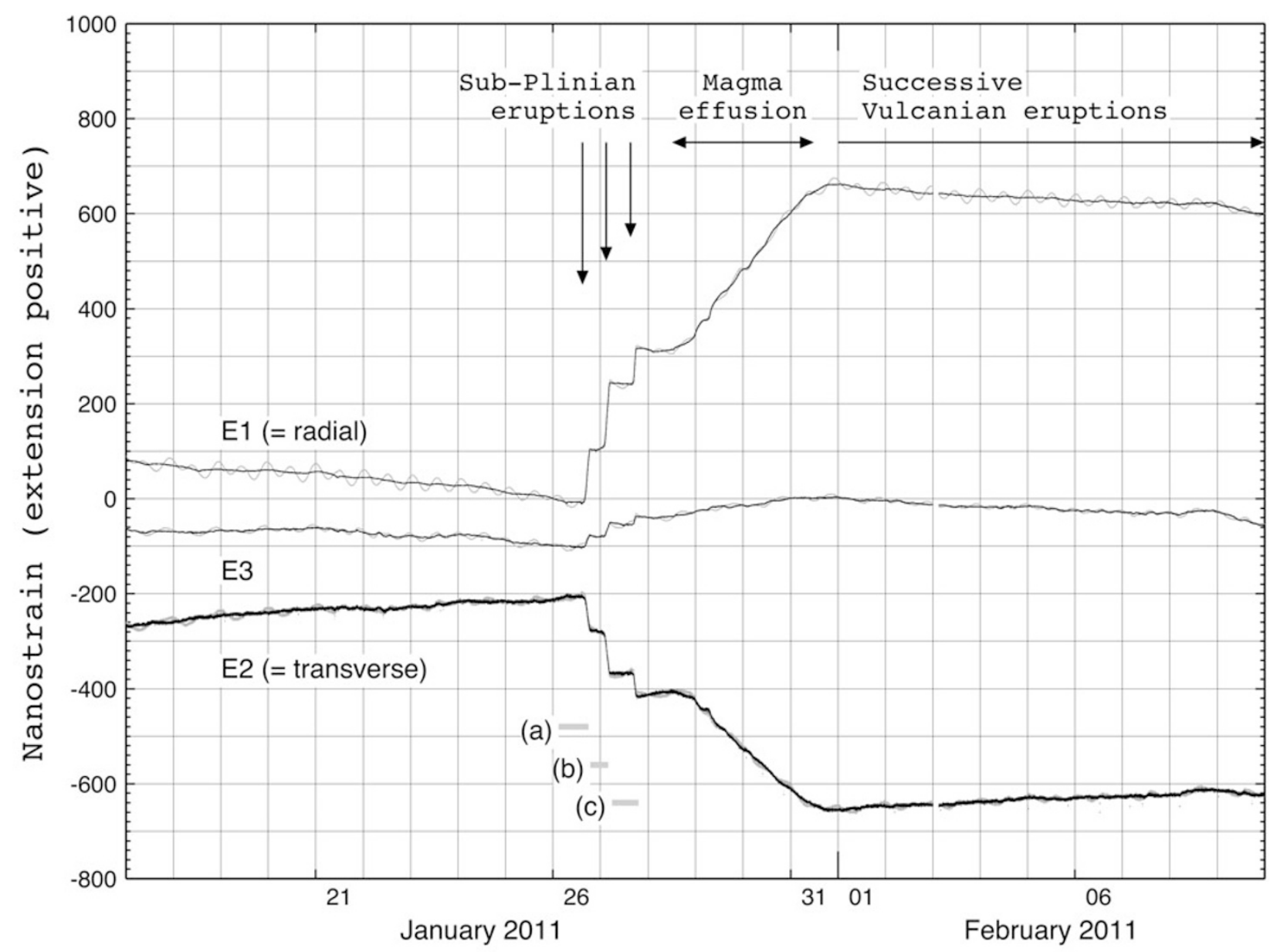

Fig. 3. Strain (extension) time series in E1-E3 directions, with black lines showing time series after the removal of tidal components, and gray lines showing the original time series data. More detailed illustrations of the time series data between the periods indicated by the gray bars (a-c) are shown in Fig. 5.

distorted significantly by precipitation (e.g., Kasahara et al., 1983), the data acquired during the 2011 Shinmoe-dake eruptions were only slightly distorted because the eruptions occurred during a period of low precipitation.

Figure 3 shows that three rapid strain changes occurred at 15:30-18:50 (local time) on 26 January, and 01:30-05:00 and 16:30-17:50 on 27 January. These three intervals correspond to the duration of the three sub-Plinian eruptions that were recorded by other means, including seismograms, infrasonic monitoring, and eyewitness observations (e.g., Earthquake Research Institute, University of Tokyo, 2011). The duration of these three strain variations, all of which were longer than 1 hour, justifies the classification of this event as a sub-Plinian eruption. A significant and gradual variation in strain was also recorded between 28 and 31 January, associated with magma effusion within the summit crater. It is reasonable to consider that these strain variations were generated by decreases in volume of pressurized magma that had been stored underground before its effusion to the surface.

The location of the magma chamber associated with the eruptions between 26 January and 1 February and the associated volume changes have already been estimated from the analysis of GPS data. By assuming the deformation was generated by an isotropic point source, the Geospa- tial Information Authority of Japan (GSI, 2011) estimated that the source was located at $31.945^{\circ} \mathrm{N}, 130.827^{\circ} \mathrm{E}$, with a depth of $6.2 \mathrm{~km}$, and that the total change in volume was $1.0 \times 10^{7} \mathrm{~m}^{3}$. The estimated horizontal location of this point source is $11.6 \mathrm{~km}$ from the ISA observatory towards $\mathrm{S} 55.75^{\circ} \mathrm{E}$, and $6.9 \mathrm{~km}$ away from the Shinmoe-dake crater towards N54.58 $\mathrm{W}$ (Fig. 1).

We have attempted to estimate the parameters of the source of these major events using extensometer-derived data, including the determination of separate source parameters for each event (i.e., the three sub-Plinian eruptions and the magma effusion event). The extensometer records on their own do not allow us to determine unique deformation source locations or volume changes in stored magma. However, we can estimate source depths and volume changes by assuming an isotropic point source and a given horizontal distance from the ISA observatory to the ground deformation epicenter.

We estimated source parameters using the following procedure. Strain changes are defined as differences between the averages of observations made during the 10 minutes immediately prior to the beginning of each event and immediately following each event. The determined strain changes associated with both sub-Plinian eruptions and the magma effusion event are listed in Table 1. The strain 
Table 1. Observed changes in strain (unit: $10^{-9}$ ) during sub-Plinian eruptions (SP1-3) and estimated isotropic point source parameters, together with estimation errors due to possible uncertainties in the observed values*1.

\begin{tabular}{|c|c|c|c|c|c|c|}
\hline \multirow[b]{2}{*}{ Event (duration) } & \multicolumn{3}{|c|}{ Observed strain change } & \multicolumn{3}{|c|}{ Estimated source parameters and errors } \\
\hline & $\mathrm{E} 1\left(\times 10^{-9}\right)$ & $\mathrm{E} 2\left(\times 10^{-9}\right)$ & $\mathrm{E} 3\left(\times 10^{-9}\right)$ & 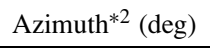 & $\operatorname{Depth}^{* 3}(\mathrm{~km})$ & Volume change $\left(\times 10^{6} \mathrm{~m}^{3}\right)$ \\
\hline SP1 (15:30-18:50, Jan 26) & $111 \pm 5$ & $-68 \pm 5$ & $25 \pm 5$ & $+2.9 \pm 2.4$ & $4.2 \pm 1.3$ & $0.89 \pm 0.07$ \\
\hline SP2 (01:50-05:00, Jan 27) & $135 \pm 5$ & $-84 \pm 5$ & $30 \pm 5$ & $+2.7 \pm 1.9$ & $4.4 \pm 1.0$ & $1.10 \pm 0.07$ \\
\hline SP3 (16:30-17:50, Jan 27) & $71 \pm 5$ & $-44 \pm 5$ & $16 \pm 5$ & $+2.7 \pm 3.7$ & $3.9 \pm 2.2$ & $0.57 \pm 0.07$ \\
\hline Magma effusion (Jan 28-30) & $333 \pm 20$ & $-239 \pm 20$ & $39 \pm 20$ & $+2.7 \pm 3.0$ & $5.7 \pm 1.2$ & $3.07 \pm 0.26$ \\
\hline
\end{tabular}

${ }^{* 1}$ Errors in observed values during magma effusion are assumed to be larger than those for SP1-3, as the duration of the effusive event was considerably longer than the duration of the sub-Plinian eruptions; this leads to changes in non-volcanic strain.

*2 Azimuth values are measured anticlockwise from the E1 direction.

${ }^{* 3}$ Depth and volume change values are estimated by assuming the horizontal distance to the source is $11.6 \mathrm{~km}$, as inferred from GPS data analysis (GSI, 2011).

changes calculated using this approach may involve uncertainties associated with non-volcanic crustal deformation during meteorological disturbances, and the presence of noise within the observation system. Short events have small errors, whereas longer events have larger errors; in addition, the E1 and E3 components have low error values, whereas the E2 component has higher inherent errors. We assume an explicit error value for each component and for each event, as given in Table 1. One of the axes of principal horizontal strain is regarded as the azimuth from the ISA observatory towards the source. Using the estimated azimuth and the assumed horizontal distance from the ISA observatory to the ground deformation epicenter, it is possible to estimate the dip angle (i.e., the angle between a horizontal plane and a direct line from the ISA site toward the source) and the volume change using the Mogi model formula of Yamakawa (1955).

The estimated source parameters are listed in Table 1, together with possible errors. The source depth for the magma effusion stage is estimated to have been slightly deeper than the source for the sub-Plinian eruptions, although these estimates are within error. These differences are likely to relate to a contribution from the volcanic conduit, where explosive (sub-Plinian) eruptions could have involved a shallow part of the magma chamber plus the conduit, yielding a shallower source depth. Note that the total volume change during the magma effusion event is larger than the sum of the volume changes during the three sub-Plinian eruptions.

These extensometer-based source parameter estimates are somewhat different from GPS-based estimates. For example, the azimuth from the site to the source is estimated to be $18^{\circ}$ by GPS, whereas the extensometer-based estimate gives an azimuth of $2^{\circ}-3^{\circ}$. The discrepancy in azimuth from ISA is $15^{\circ}-16^{\circ}$ as illustrated in Fig. 4. In addition, the GPS-based estimate of the source depth is about $6.2 \mathrm{~km}$ (e.g., GSI, 2011), whereas all extensometer-derived source depth estimates are $<5.7 \mathrm{~km}$ (Table 1). Furthermore, the entire GPS-based volume change estimate is larger than the total of the extensometer-based volume changes for all four major events, with the GPS-based analysis yielding a volume change of $7.2 \times 10^{6} \mathrm{~m}^{3}$, whereas the extensometerbased estimate was $5.63 \pm 0.07 \times 10^{6} \mathrm{~m}^{3}$. Source parameters for the total amount of deflation during the three sub-Plinian eruptions and the magma effusion are also estimated by Ueda et al. (2013) and Nakao et al. (2013) by using geodetic

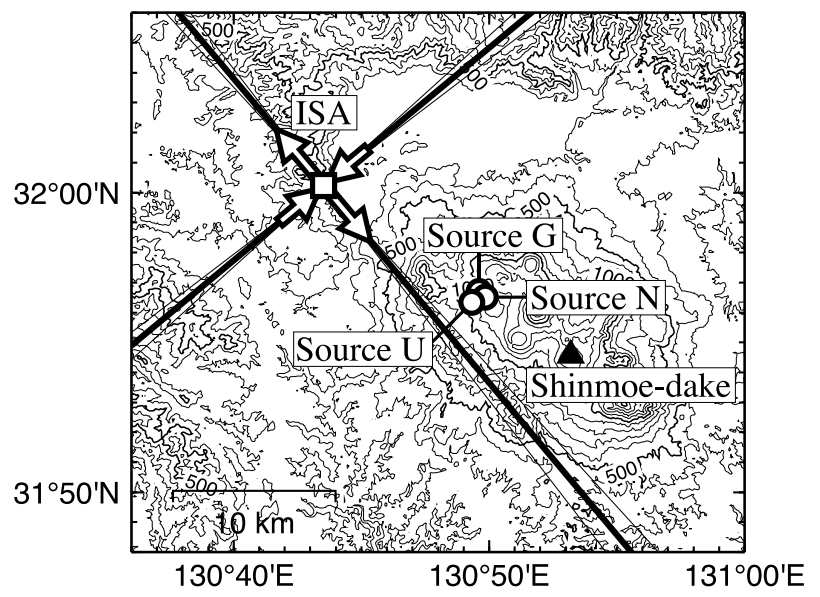

Fig. 4. Geometrical relationship between the principal strain axes (thick lines) at ISA determined for the first sub-Plinian eruption on 26 January, 2011, and the location of Shinmoe-dake crater. Arrows show the direction (i.e. compression or depression) in each direction. Thin lines show the range of the estimation error. Open circles with text labels (Source $\mathrm{G}$, Source U, and Source N) indicate the horizontal locations of deflation point sources during the sub-Plinian and the magma effusion event estimated by GSI (2011), Ueda et al. (2013), and Nakao et al. (2013), respectively.

data. By their analysis, depths of the source are estimated to be $9.8 \mathrm{~km}$ and $8.35 \mathrm{~km}$, and volume changes are estimated to be $13.2 \times 10^{6} \mathrm{~m}^{3}$ and $13.35 \times 10^{6} \mathrm{~m}^{3}$, respectively. Both of these values are larger than the extensometer-based estimate. The extensometer-based estimate highly depends on the assumed horizontal distance. If we assume the horizontal distance is $15 \mathrm{~km}$, the depth and total volume changes estimated by extensometers are up to $7.4 \mathrm{~km}$ and $12.32 \times 10^{6}$ $\mathrm{m}^{3}$, respectively, which are smaller than those estimated by Nakao et al. (2013), and Ueda et al. (2013), but larger than that estimated by GSI (2011).

In general, estimating the location and size of deformation sources using data obtained from a single observatory may introduce significant errors, as the data obtained at this observatory may be distorted, for example by variations in local elastic properties around the site. An approach using model idealization that ignores possible contributions from a finite-length conduit may also introduce errors. As documented above, estimates based on strain data obtained 
(a)

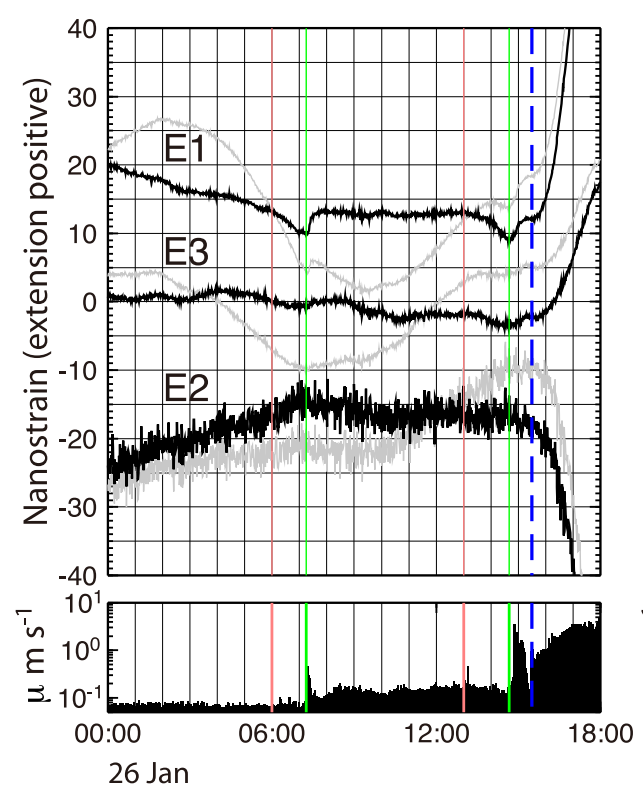

(b)

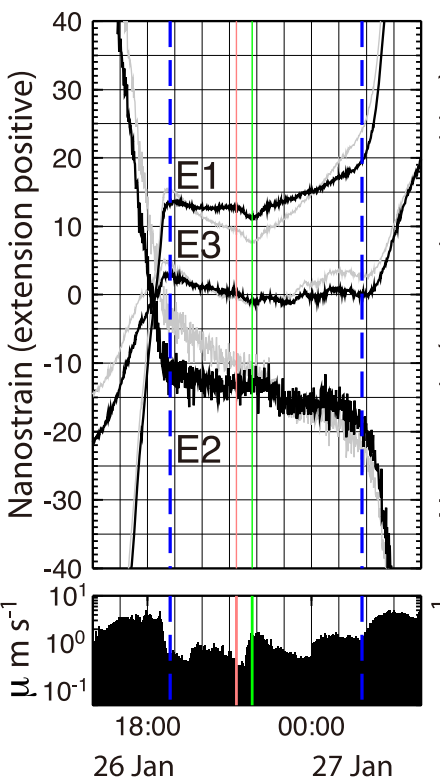

(c)

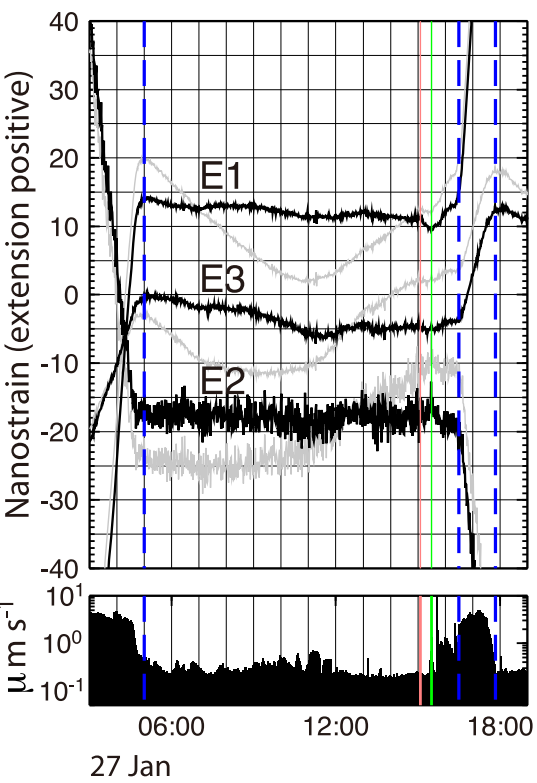

Fig. 5. Detailed views of strain time series prior to each sub-Plinian eruption. Time ranges in a-c correspond to the gray bars in Fig. 3 (i.e., 00:00-18:00 on 26 January, 16:00 on 26 January to 04:00 on 27 January, and 03:00-19:00 on 27 January, respectively). Black lines represent strain time-series after tidal components are removed, with gray lines representing the original time series. Shadowed graphs at the bottom represent ground velocities at the Takachihogawara seismic station (Fig. 1). Vertical lines in red and green indicate onsets of inflation and deflation, respectively.

from the ISA observatory differ from estimates based on data from multiple stations. However, the differences are rather small.

The volumes of lava and tephra produced between 26 and 31 January, 2011, were also estimated by other means. Field measurements suggest that $24 \times 10^{6} \mathrm{~kg}$ of tephra was produced during the three sub-Plinian eruptions (National Institute of Advanced Industrial Science and Technology (AIST) and Asia Air Survey Co., Ltd., 2011), and assuming a density of $2500 \mathrm{~kg} / \mathrm{m}^{3}$ yields a dense rock equivalent volume of $9.6 \times 10^{6} \mathrm{~m}^{3}$. Additional estimates used a photograph taken on 31 January, 2011, which suggests the volume of lava accumulated in the Shinmoe-dake summit crater was $14 \times 10^{6} \mathrm{~m}^{3}$ (Earthquake Research Institute et al., 2011). The magma extruded as lava is approximately 1.4 times larger than that ejected as tephra. The volume change estimated from extensometer records is $2.56 \times 10^{6}$ $\mathrm{m}^{3}$ and $3.07 \times 10^{6} \mathrm{~m}^{3}$, respectively, for the three subPlinian eruptions and magma effusion (Table 1) and the ratio of magma effusion to sub-Plinian eruptions is 1.2. Both field and photograph-based measurements are larger than the extensometer-based volume estimates presented here, but the ratio approximately coincides with each other. This indicates that the strain data obtained at the ISA observatory can detect more detail volcanic process and may provide approximate but reasonable depth and volume change estimates for other volcanic events.

\section{Subtle Changes in Strain Prior to the Sub- Plinian Eruptions}

In addition to the major strain changes that occurred simultaneously with the major eruptive events, subtle strain changes can be detected before each sub-Plinian eruption by visual inspection of the extensometer data. Figure 5 gives a detailed view of the strain time-series data for the periods covering several hours before each sub-Plinian eruption. Before the start of the first sub-Plinian eruption at around 15:30 on 26 January, 2012, pairs of gradual decreases and rapid increases in the E1 component of strain (i.e., contraction and subsequent extension) with amplitudes of $\sim 3 \times 10^{-9}$ were recorded at approximately 6:00-7:40 and 13:00-15:10 on 26 January (Fig. 5(a)). Subtle strain variations were also seen at 21:15-22:20 on 26 January and 15:05-16:00 on 27 January, prior to the second and third sub-Plinian eruptions (Fig. 5(b and c)), and the amplitudes of these precursory strain changes were approximately $2 \times 10^{-9}$, somewhat smaller than those associated with the first eruption. The magnitudes of these subtle deformations (i.e., $\sim 1 \times 10^{-9}$ ) are two orders of magnitude smaller than the strain changes observed during each subPlinian eruption (i.e., $\sim 100 \times 10^{-9}$ ).

The subtle inflation followed by rapid deflation recorded during each event seems to be associated with a causal process associated with each sub-Plinian eruption. However, it is unclear whether this hypothesis is plausible, as similarsized strain variations that are not associated with volcanic processes may have also been measured. Further research is needed to determine whether similar strain changes are only recorded before the three sub-Plinian eruptions that form the focus of this study. We investigated this possibility by analyzing the rate of variation in the E1 component strain. To obtain the strain rate values, the derivative of the smoothed time series trend was calculated. The smoothed time series trend was obtained following Tamura et al. (1991), with ABIC used to determine the optimum parameter that controls the smoothness of the trend. Because of the smoothing process, phenomena with time scales less than 30 minutes are ignored; however, it does not affect the 
(a)

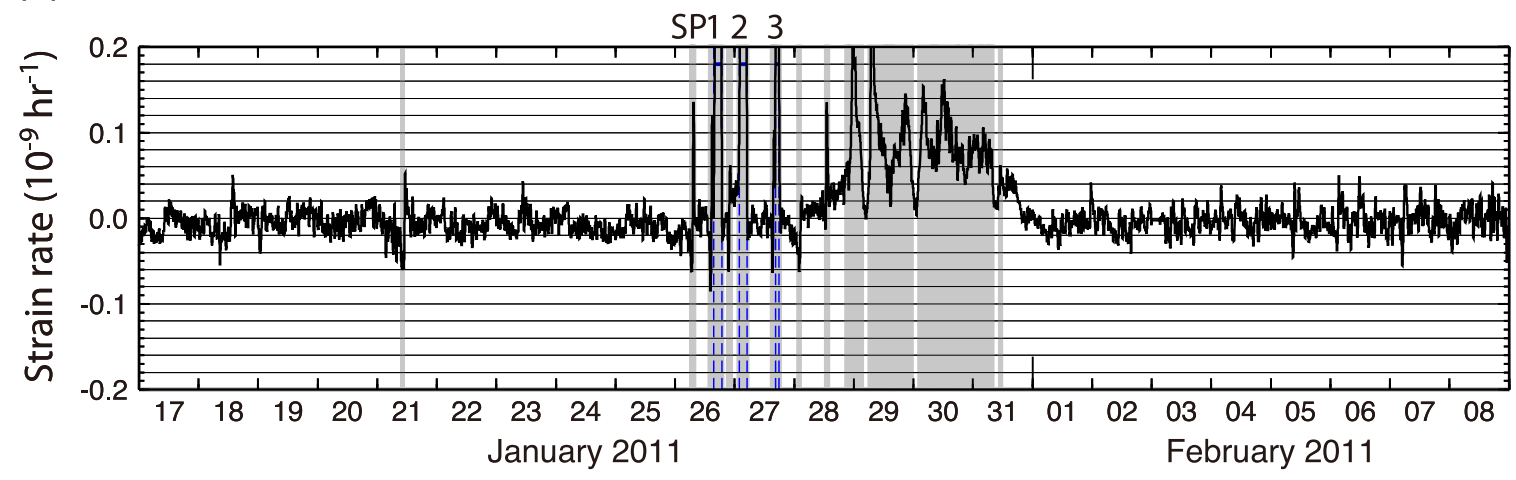

(b)
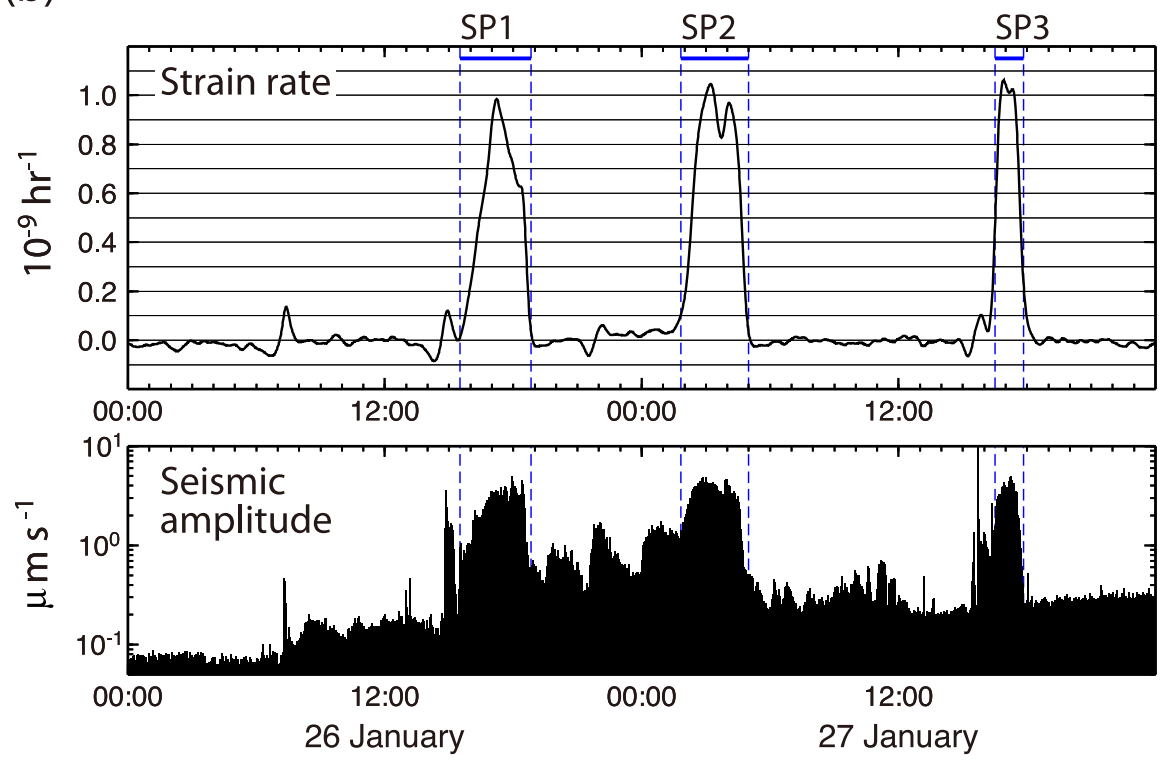

Fig. 6. (a) E1 component strain rates between 17 January and 8 February, 2011; SP1, 2, and 3 denote the first, second, and third sub-Plinian eruptions, respectively, that form the focus of this study, and the shaded gray area indicates periods with strain rates of $>0.6 \times 10^{-9}$. (b) E1 component strain rates between 26 and 27 January, 2011, with the lower panel showing simultaneous ground velocity changes at the Takachihogawara seismic station (Fig. 1).

following discussion.

Figure 6(a) shows strain rates together with periods with strain rates greater than the rates associated with the subtle changes that precede sub-Plinian eruptions (i.e., $0.6 \times 10^{-9}$ $\mathrm{h}^{-1}$ ). The figure shows only one example of a sizable change in strain rate in the E1 direction that was not associated with sub-Plinian eruptions or subsequent magma effusion. This change was recorded on 21 January, 2011, and was followed by a minor eruption event on 22 January, 2011. This observation indicates that subtle changes in strain are commonly followed by sub-Plinian eruptions, although the relationship between eruptions and preceding deformation is not exactly one-to-one. In other words, these strain changes are a kind of precursory phenomenon associated with sub-Plinian eruptions. Similar precursory ground deformation has already been identified for Vulcanian eruptions at Sakurajima (Ishihara, 1990) and Montserrat (Voight et al., 1998, 1999), and the data presented here suggest that these precursory phenomena are also present before other types of eruption.

Contraction and subsequent extension in the E1 direction are probably associated with inflation and subsequent deflation of the point source. However, the amplitudes of the subtle precursor changes are small and have low signal/noise ratios, meaning that accurately determining the parameters of the source of these changes is impossible, unlike the changes associated with the sub-Plinian eruptions and the magma effusion event. Nevertheless, we can obtain a possible range of source locations for the first subtle strain change using the following procedure. This approach is similar to that discussed in Section 3, in that we assume that the deformation was generated by an isotropic point source that was located approximately in the same direction as the orientation of the E1 vault within the ISA observatory, meaning that the E1 and E2 components are approximate radial and transverse strain components, respectively. The first subtle strain change was associated with an E1 component strain change of $-4 \times 10^{-9}$, with an E2 component change of up to $+2 \times 10^{-9}$. The significant noise and fluctuations within the E2 component signal mean that this value is not very precise. However, it is apparent by visual inspection that even if we assume that the possible error in the E1 component is $+0.5 \times 10^{-9}$, the E2/E1 ratio is unlikely to be less than -0.7 . This value of -0.7 


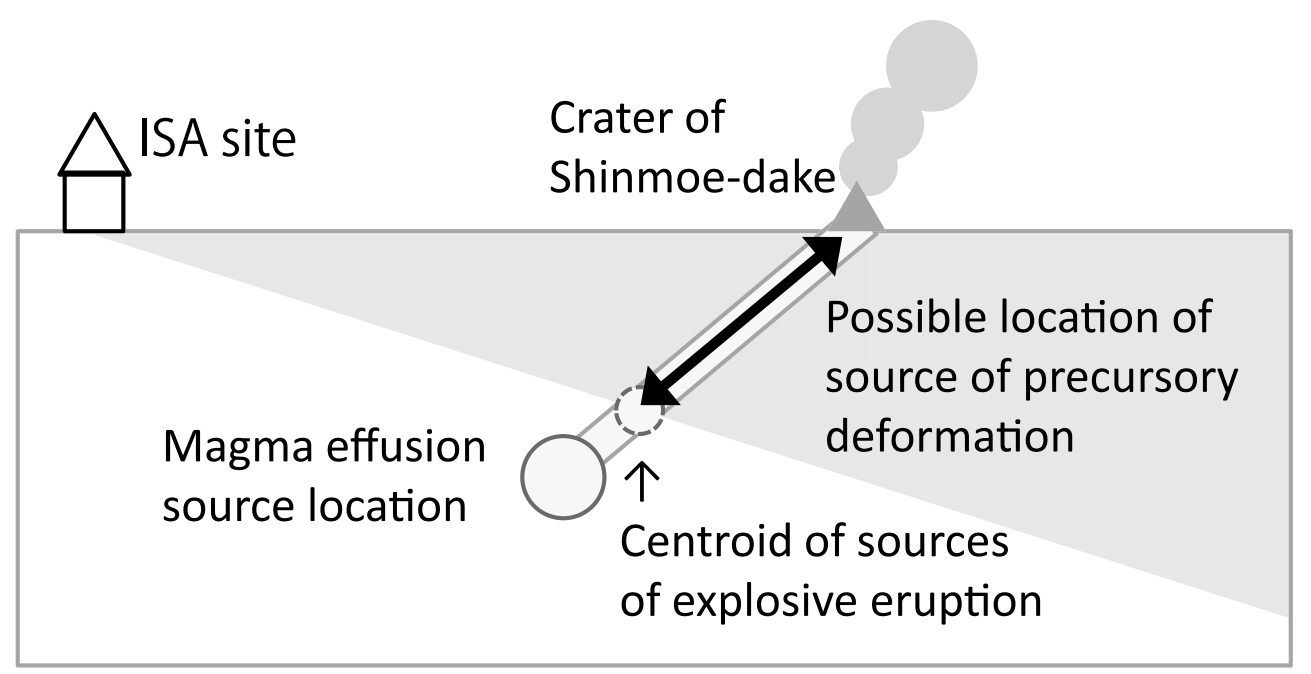

Fig. 7. Schematic geometry of the ISA observatory, showing the relative locations of Shinmoe-dake volcano, the eruption-related magma chamber, the centroid for the explosive eruptions, and possible source locations associated with the precursory deformation. The shaded area indicates potential source areas for these subtle strain changes.

is comparable to the E2/E1 ratios obtained for the major events, indicating that the dip angle to an isotropic point source should be smaller than the dip angle for the precursory subtle strain change should be smaller than that for the major sub-Plinian events (Fig. 7).

The above discussion further indicates that if the horizontal distance from the ISA site to the source epicenter was the same for both the precursory deformation and the subPlinian eruptions, the source depth of the precursory deformation would have been shallower than the source depth of the magma chamber, at least for the first subtle strain event that was recorded at around 6:00-7:40 on 26 January, 2011. Even if this horizontal distance to the source is not fixed, the source depth is still likely to be shallow unless the horizontal distance is very large (Fig. 7).

Other geophysical acquisition techniques (e.g., Kato and Fujiwara, 2012; Maehara et al., 2012), including eyewitness reports, provided several other records of phenomena prior to the sub-Plinian eruptions. In the case of the first sub-Plinian eruption, for example, an increase in seismic amplitudes was observed at about 7:15 (Fig. 5(a)), coincident with the onset of a rapid extension recorded in the E1 direction (Fig. 5(a)). A minor ash eruption with increased amounts of volcanic smoke was observed at this same time, and was followed by a further increase in the amount of volcanic smoke venting at around 7:50. At about 14:50, seismic amplitudes increased again (Fig. 5(a)), which corresponds to the subtle deformation just before the first subPlinian eruption. At this time, steam emissions were also observed (Maehara et al., 2012). Increases in seismic amplitudes were again observed in association with the subtle deformations before the second and third sub-Plinian eruptions, although the exact timings of the onset of these two sets of phenomena are not exactly the same (Fig. 5(b and c)).

\section{Discussion}

The precursory deformation associated with each of the sub-Plinian eruptions documented in this study can be in- terpreted as follows: a gradual E1 component contraction corresponds to the accumulation of volcanic gases at depth, and a rapid extension of the E1 component corresponds to decreasing pressure during the release of volcanic gases within the crater. The shallow source depth estimates for these precursory deformation events is consistent with this interpretation. If this interpretation is correct, temporal changes in strain will be important factors in any further investigation of these processes.

Similarities between the subtle strain changes (indicated by variations in strain rates from negative to positive) prior to each of the sub-Plinian eruptions are also evident in the strain rate graph shown in Fig. 6(b). The shapes of subtle strain changes for each of the sub-Plinian eruptions are similar, suggesting that the precursory phenomena corresponding to each sub-Plinian eruption involve similar processes.

Figure 6(b) also shows, however, that the relationships between subtle changes in strain and the eruptions are not simple. For example, the first eruption on 26 January was associated with two subtle changes in strain: one approximately 8 hours before the eruption and a second at 15:00$15: 30$, immediately prior to the eruption. The second eruption occurred around 3 hours after the subtle strain change at 21:20-22:20 on 26 January. The last sub-Plinian eruption was almost simultaneous with the ending of this period of subtle strain change. In summary, the time interval between the beginning of the subtle strain change and each sub-Plinian eruption decreased over time. It may also be noted that variations are also apparent in the speeds of deflation during sub-Plinian eruptions

The variations in the timing relationships between subtle strain changes, increases in seismic amplitudes, and the onset of sub-Plinian eruptions, together with the increasing rate of deflation during each eruption may be related to changes either in the magma properties or in the magma supply system (e.g., magma viscosity, expansion of a magma conduit as a result of repeated eruptions, or gradual magma ascent). Additional discussion requires at least a quantitative estimation of the location and magnitude of 
subtle strain changes.

Further investigation requires other geophysical datasets. Because the direct measurement of strain of the order of $10^{-9}$ was performed at only one site, some other approach is required to investigate the precursory deformation more fully. The use of broadband seismograms may be a promising way to deduce tilt changes at particular points (e.g., Aoyama and Oshima, 2008). In fact, tilt changes prior to the sub-Plinian eruptions of Shinmoe-dake were indicated by data from a broadband seismogram positioned about 1 $\mathrm{km}$ from the crater of Shinmoe-dake (Maehara et al., 2012). Combining such a result with direct measurements of strain would make it possible to estimate the sizes and locations of the sources of precursory crustal deformation more accurately, which, in turn, would improve our understanding of the processes involved in the sub-Plinian eruptions.

\section{Conclusions}

Subtle (order $10^{-9}$ ) strain changes were recorded prior to sub-Plinian eruptions during the activities of Shinmoedake in January 2011 by using vault-housed extensometers installed approximately $18 \mathrm{~km}$ away from the summit crater of the volcano. Each subtle strain change can be accounted for by an inflation followed by a deflation at depth. The depth of the source is estimated to be shallower than the magma chamber that produced most of the effusive material during the eruptions of Shinmoe-dake. This may indicate that the movement of magma or volcanic gas from the main magma chamber towards the ground surface occurred not only during the sub-Plinian eruptions but also before these eruptions. The observed subtle changes in strain provide significant constraints on the possible mechanisms of the sub-Plinian eruptions of Shinmoe-dake, although further studies using other geophysical datasets are required if we are to investigate the processes more fully.

Acknowledgments. Observations at Isa and Yoshimatsu were supported by staff of the DPRI, Kyoto University, particularly Yasumi Sonoda and Tetsuro Takayama. The program Generic Mapping Tools (Wessel and Smith, 1998) was used to prepare some of the figures presented here. Comments on an earlier version of the manuscript by Barry Voight and anonymous reviewers helped us to significantly improve both the content and the presentation of this manuscript.

\section{Appendix A.}

Here, we consider the procedure of evaluating minimum sizes of subsurface volumetric changes that can be resolved by GPS and by extensometers.

First, the detection limit of GPS is considered. Only horizontal displacements are considered here because the vertical component of GPS data is generally less accurate. In the case of a point source model (i.e., a Mogi model), the horizontal displacement in a radial direction from the source, denoted by $u_{r}$, is expressed as

$$
u_{r}(r)=\frac{\lambda+2 \mu}{2 \pi(\lambda+\mu)} \Delta V \frac{r}{\left(r^{2}+f^{2}\right)^{3 / 2}}
$$

where $\lambda$ and $\mu$ are Lamé constants, $r$ is the horizontal distance, and $f$ is the source depth. Assume $u_{\min }$ is the minimum displacement that GPS can resolve. A volume

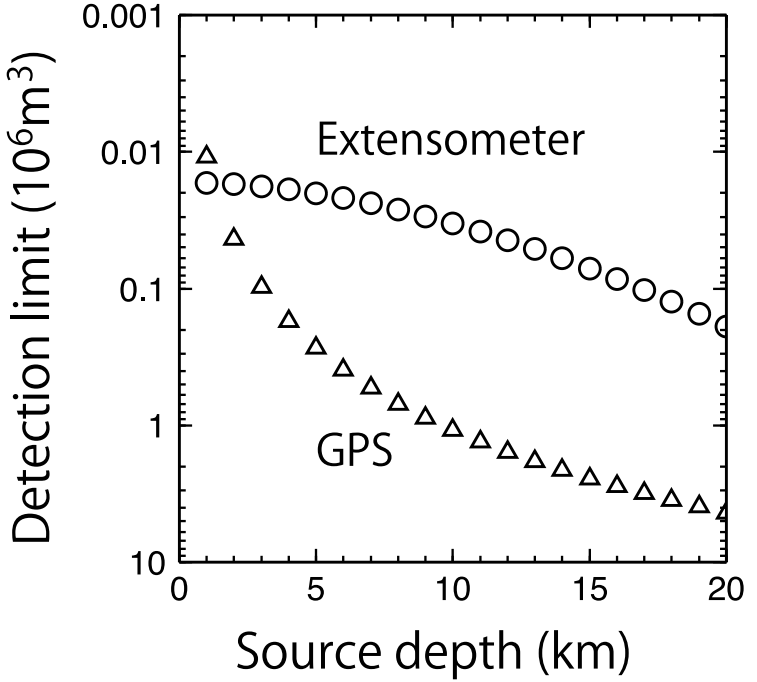

Fig. A.1. Detection limits of subsurface volume changes by using extensometers at $20 \mathrm{~km}$ away from the epicenter (circles), and by using GPS installed at an optimum point (triangles). The extensometer is assumed to be set in the radial direction from the source. GPS measures the horizontal displacement. Resolutions of extensometers and GPS are assumed to be $1.0 \times 10^{-9}$ (dimensionless) and $1.0 \mathrm{~mm}$, respectively.

change $\Delta V$ can be detected by GPS if (A.1) is larger than $u_{\min }$. This condition is expressed by

$$
\Delta V \geq \frac{2 \pi(\lambda+\mu)}{\lambda+2 \mu} \frac{\left(r^{2}+f^{2}\right)^{3 / 2}}{r} u_{\min } .
$$

The right-hand side of (A.2) is minimized when $r=f / 2^{1 / 2}$. Provided that GPS stations are installed with a sufficient spatial density, we can choose $r$ so that the right-hand side of (A.2) is minimized. Therefore, in the case of $\lambda=\mu$, we derive the following condition

$$
V \geq 2 \sqrt{3} \pi f^{2} u_{\min }
$$

This provides the minimum size of the subsurface volume change $(\Delta V)$ that can be monitored by the GPS array.

Next, the detection limit of extensometers is considered. Let us consider the extension in a radial direction from the source, denoted by $E_{r}$. It is expressed as

$$
E_{r}=\frac{\partial}{\partial r} u_{r}(r)=\frac{\lambda+2 \mu}{2 \pi(\lambda+\mu)} \Delta V \frac{-2 r^{2}+f^{2}}{\left(r^{2}+f^{2}\right)^{5 / 2}} .
$$

Assume $E_{\min }$ is the minimum displacement that GPS can detect. Similar to GPS, a volume change $\Delta V$ can be detected by extensometers if (A.1) is larger than $E_{\min }$. This condition is expressed by

$$
\Delta V \geq \frac{2 \pi(\lambda+\mu)}{\lambda+2 \mu} \frac{\left(r^{2}+f^{2}\right)^{5 / 2}}{-2 r^{2}+f^{2}} E_{\min } .
$$

In contrast to the case of GPS, the data from the extensometers are not expected to be available at arbitrary points. Therefore, a fixed value of $r$ should be used to evaluate the minimum size of the detectable volume change by using (A.4).

An example of an evaluation using (A.3) and (A.5) is shown in Fig. A.1. 


\section{References}

Akaike, H., Likelihood and Bayes Procedure, in Bayesian Statistics, edited by Bernardo, J. M., M. H. DeGroot, D. V., Lindley, D. V. and A. F. M. Smith, 143-166, University Press, Valencia, 1980.

Aoyama, H. and H. Oshima, Tilt change recorded by broadband seismometer prior to small phreatic explosion of Meakan-dake volcano, Hokkaido, Japan, Geophys. Res. Lett., 35, L06307, 2008.

Chardot, L., B. Voight, R. Stewart, S. I. Sacks, A. Linde, D. Hidayat, A. Clarke, D. Elsworth, R. Foroozan, J.-C. Komorowski, G. S. Mattioli, and S. Sparks, Explosion dynamics from strainmeter and microbarometer observations, Soufrière Hills Volcano, Montserrat: 2008-2009, Geophys. Res. Lett., 37, L00E24, 2010.

Druitt, T. H., S. R. Young, T. Baptie, C. Bonadonna, E. S. Calder, A. B. Clarke, P. D. Cole, C. L. Harford, R. A. Herd, R. Luckett, G. Ryan, and B. Voight, Episodes of cyclic Vulcanian explosive activity with fountain collapse at Soufrière Hills Volcano, Montserrat, in The Eruption of Soufrière Hills Volcano, Montserrat, from 1995 to 1999, edited by T. H. Druitt and B. P. Kokelaar, Geological Society Memoir No. 21, 281-306, 2002.

Dvorak, J. J. and D. Dzurisin, Volcano geodesy: the search for magma reservoirs and the formation of eruptive vents, Rev. Geophys., 35, 343384, 1997.

Earthquake Research Institute, University of Tokyo, Eruption of Shinmoe-dake (Kirishima volcano group), Japan, 2011. (URL: http://outreach.eri.u-tokyo.ac.jp/eqvolc/201101_shinmoe/eng/; last updated on 22 Feb 2011; last accessed, 5 Jul 2013).

Earthquake Research Institute, the University of Tokyo, Kagoshima University, Hokkaido University, and Kokusai Kogyo, Co. Ltd., Volume of lava in the crater of Shinmoe-dake on Jan 31, 2011, material presented at the 118th meeting of Coordinating Committee for Prediction of Volcanic Eruption, 15 February 2011. (in Japanese; URL: http://www.eri.utokyo.ac.jp/imoto/ERI_kirishima_geology_rev.pdf; last access, 18 Jun 2013).

Geospatial Information Authority of Japan, Crustal deformation around Kirishima Volcano, Rep. Coord. Comm. Predict. Volcan. Erupt., 108, 197-220, 2011 (in Japanese).

Iguchi, M., H. Yakiwara, T. Tameguri, M. Hendrasto, and J. Hirabayashi, Mechanism of explosive eruption revealed by geophysical observations at the Sakurajima, Suwanosejima and Semeru volcanoes, J. Volcanol. Geotherm. Res., 178, 1-9, 2008.

Ishihara, K., Pressure sources and induced ground deformation associated with explosive eruptions at an andesitic volcano: Sakurajima volcano, Japan, in Magma Transport and Storage, edited by Ryan, M., 335-356, Wiley, New York, 1990.

Japan Meteorological Agency, Catalog of Active Volcanoes in Japan (English version), 3rd edition, 2005.

Kamo, K. and K. Ishihara, Precursor of summit eruption observed by water-tube tiltmeters and extensometers, Annuals Disas. Prev. Res. Inst., Kyoto Univ., 29B-1, 1-12, 1986 (in Japanese with English abstract).

Kasahara, M., R. Shichi, and Y. Okada, On the cause of long-period crustal movement, Tectonophysics, 97, 327-336, 1983.

Kato, K. and Y. Fujiwara, The tilt change preceding magmatic eruption of Shinmoedake Volcano, paper presented at Annual meeting of Volcanological Society of Japan, Miyoda, Nagano, Japan, 14-16 October, 2012 (in Japanese).

Linde, A. T., K. Agustsson, I. S. Sacks, and R. Stefansson, Mechanism of the 1991 eruption of Hekla from continuous borehole strain monitoring, Nature, 365, 737-740, 1993.

Linde, A., S. I. Sacks, D. Hidayat, B. Voight, A. Clarke, D. Elsworth, G.
S. Mattioli, P. Malin, E. Shalev, S. Sparks, and C. Widiwijayanti, The Vulcanian explosion at Soufrière Hills Volcano, Montserrat on March 2004 as revealed by strain data, Geophys. Res. Lett., 37, L00E07, 2010. Maehara, Y., M. Takeo, T. Ohminato, M. Ichihara, and J. Oikawa, Tilt motions associated with sub-Plinian, Vulcanian eruptions, and an effusive stage in the 2011 Shinmoe-dake eruption, Paper presented at Japan Geoscience Union Meeting 2012, Chiba, Japan, 20-25 May, 2012.

Nakao, S., Y. Morita, H. Yakiwara, J. Oikawa, H. Ueda, H. Takahashi, Y. Ohta, T. Matsushima, and M. Iguchi, Volume change of the magma reservoir relating to the 2011 Kirishima Shinmoe-dake eruptionCharging, discharging and recharging process inferred from GPS measurements, Earth Planets Space, 65, 505-515, 2013.

National Institute of Advanced Industrial Science and Technology (AIST) and Asia Air Survey co., Ltd., Amount of tephra effused from Shinmoe-dake after Jan 26, 2011, material presented at 120th meeting of Coordinating Committee for Prediction of Volcanic Eruption, 7 June 2011 (in Japanese; URL: https://www.gsj.jp/hazards/volcano/kirishima2011/works-history.html; last access, 18 Jun 2013).

Peltier, A., T. Staudacher, P. Catherine, L.-P. Ricard, P. Kowalski, and P. Bachelery, Subtle precursors of volcanic eruptions at Piton de la Fournaise detected by extensometers, Geophys. Res. Lett., 33, L06315, 2007.

Tamura, Y., T. Sato, M. Ooe, and M. Ishiguro, A procedure for tidal analysis with a Bayesian information criterion, Geophys. J. Int., 104, 507-516, 1991.

Ueda, H., T. Kozono, E. Fujita, Y. Kohno, M. Nagai, Y. Miyagi, and T. Tanada, Crustal deformation associated with the 2011 Shinmoe-dake eruption as observed by tiltmeters and GPS, Earth Planets Space, 65 , 517-525, 2013.

Voight, B., R. P. Hoblitt, A. B. Clarke, A. B. Lockhart, A. D. Miller, L. Lynch, and J. McMahon, Remarkable cyclic ground deformation monitored in real time on Montserrat and its use in eruption forecasting, Geophys. Res. Lett., 25, 3405-3408, 1998.

Voight, B., R. S. J. Sparks, A. D. Miller, R. C. Stewart, R. P. Hoblitt, A. Clarke, J. Ewart, W. P. Aspinall, B. Baptie, E. S. Calder, P. Cole, T. H. Druitt, C. Hartford, R. A. Herd, P. Jackson, A. M. Lejeune, A. B. Lockhart, S. C. Loughlin, R. Luckett, L. Lynch, G. E. Norton, R. Robertson, I. M. Watson, R. Watts, and S. R. Young, Magma flow instability and cyclic activity at Soufrière Hills Volcano, Montserrat, British West Indies, Science, 283, 1138-1142, 1999.

Voight, B., D. Hidayat, S. I. Sacks, A. Linde, L. Chardot, A. Clarke, D. Elsworth, R. Foroozan, G. S. Mattioli, N. McWhorter, S. Sparks, and C. Widiwijayanti, Unique strainmeter observations of Vulcanian explosions, Soufrière Hills Volcano, Montserrat, July 2003, Geophys. Res. Lett., Special Section on Montserrat, 37, L00E18, 2010.

Wessel, P. and W. H. F. Smith, New, improved version of Generic Mapping Tools released, Eos Trans. AGU, 79, 579, 1998.

Yamakawa, N., On the strain produced in a semi-infinite elastic solid by an interior source of stress, Zishin 2nd series (J. Seismol. Soc. Jpn.), 8, 84-98, 1955.

Yamazaki, K., M. Teraishi, S. Komatsu, Y. Sonoda, and Y. Kano, On the possibility of the 2011 Tohoku-oki earthquake reactivating Shinmoedake volcano, southwest Japan: insights from strain data measured in vaults, Nat. Haz. Earth Syst. Sci., 11, 2655-2661, 2011.

K. Yamazaki (e-mail: kenichi@rcep.dpri.kyoto-u.ac.jp), M. Teraishi, K. Ishihara, S. Komatsu, and K. Kato 